\title{
IMPROVED SWITCHING SELECTION FOR DTC OF INDUCTION MOTOR DRIVE USING ARTIFICIAL NEURAL NETWORKS
}

\author{
Habib BENBOUHENNI \\ Ecole Nationale Polytechnique d'Oran Maurice Audin, Oran, Algeria, \\ E-mail: habib_benbouhenni@yahoo.com
}

\begin{abstract}
Direct Torque Control (DTC) is a control technique in AC drive systems to obtain high performance torque ripple. This paper also proposes improvement of the conventional DTC without voltages zeros using the improvement of the switching table and the application of the Artificial Neural Network (ANN) to minimize the torque ripple, stator flux ripple and Total Harmonic Distortion (THD) value of stator current and to get better performance of the induction motor (1MW) controlled by DTC, by using two-level inverter. The comparison with conventional direct torque control, show that the use of the proposed strategies with ANN, reduced the torque ripple, stator flux ripple and total harmonic distortion value of stator current. The validity of the proposed strategies is confirmed by the simulative results.
\end{abstract}

Keywords: induction motor, direct torque control, switching table, artificial neural network, total harmonic distortion, voltages zeros, two-level inverter

\section{INTRODUCTION}

Induction motor (IM) has achieved popularity in industrial application due to its low cost, reliability, low maintenance, no brushes to wear out, very simple rotor assembly and no magnets to add to the cost. Squirrel cage induction machine when operated constant line voltage $(60 \mathrm{~Hz})$ it operates at constant speed. However in industries we have variable speed applications of Induction motors. This can be achieved by Induction motor drives [1].

The drive control system is necessary for IMs. Though DC motor is able to provide desired performance, its maintenance and unsafe in explosive environment restricts its use. In 1970s, field oriented control (FOC) scheme proved success for torque and speed control of induction motor. Decoupling of two components of stator currents (flux and torque producing components) is achieved as DC machines to provide independent torque control. Hence the scheme proves itself superior to the DC machine. The problem faced by FOC scheme is complexity in its implementation due to dependence of machine parameters, reference frame transformation. Later DTC was introduced. The method requires only the stator resistance to estimate the stator flux and torque [2].

Direct Torque Control (DTC) method has been first proposed and applied for induction machines in the mid1980 's as reported in [3]. In conventional DTC, electromagnetic torque and flux are independently controlled by selection of optimum inverterswitching modes. The selection of optimum inverter switching modes is made to limit the electromagnetic torque and flux linkage errors within the torque and flux hysteresis bands. The basic DTC scheme consists of two comparators with specified bandwidth, switching table, and voltage source inverter, flux and torque estimation block. Like every control method has some advantages and disadvantages, DTC method has too. Some of the advantages are lower parameters dependency, making the system more robust and easier to implements and the disadvantages are the difficulty of controlling flux and torque at low speed, current and torque distortion during the change of the sector, variable switching frequency, a high sampling frequency needed.

For digital implementation of hysteresis controllers, high torque ripples. The torque ripple generates noise and vibrations, causes errors in sensor less motor drives, and associated current ripples are in turn responsible for the EMI. The reason of the high current and torque ripple in DTC is the presence of hysteresis comparators together the limited number of available voltage vectors [2].

The basic disadvantages of DTC scheme using hysteresis controllers are the variable switching frequency, the current and torque ripple. In the aim to improve the performance of the electrical drives based on traditional DTC, fuzzy logic direct torque control (FLDTC) and artificial neural network direct torque control (DTC-ANN) attracts more and more the attention of many scientists [4]. This paper is devoted to DTC-ANN of sensorless induction motor fed by two-level.

\section{THE CONVENTIONAL DTC}

The structure of the conventional DTC was shown in Fig. 1, it which consists of two hysteresis comparator, torque and flux estimators, voltage vector selector and voltage source inverter (VSI) [5].

The direct torque control method uses an induction motor model to predict the voltage required to achieve a desired output torque. By using only current and voltage measurements, it is possible to estimate the instantaneous stator flux and output torque. The flux and torque are controlled by two comparators with hysteresis two and three level respectively. The switching table is shown in Table 1 determines the voltage vector to apply based on the position of the stator flux and the required changes in stator flux magnitude and torque. The selected voltage vector will be applied to the induction motor at the end of the sample time in VSI [5]. 


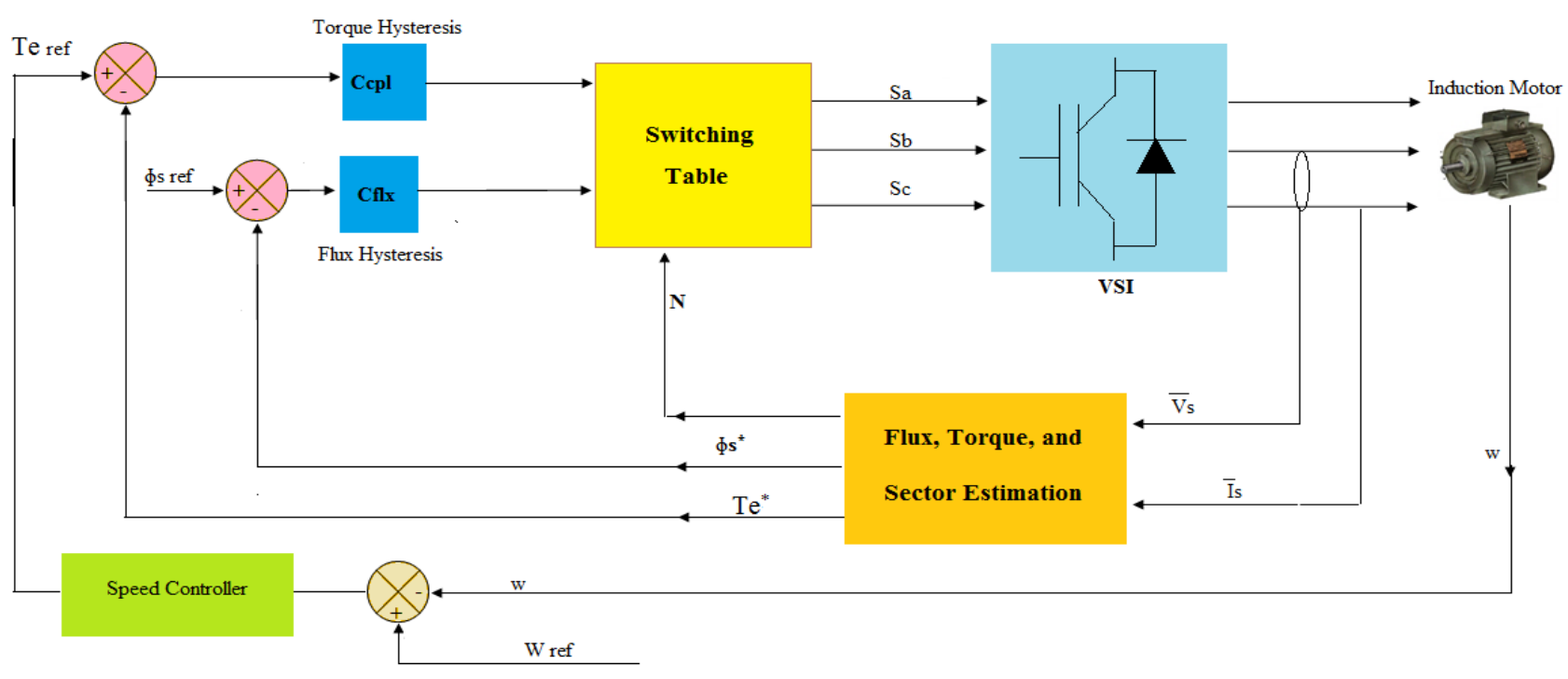

Fig. 1 Classical direct torque control scheme for induction motor

Table 1 Switching table for classical DTC

\begin{tabular}{|c|c|c|c|c|c|c|c|}
\hline \multicolumn{2}{|c|}{ N } & $\mathbf{1}$ & $\mathbf{2}$ & $\mathbf{3}$ & $\mathbf{4}$ & $\mathbf{5}$ & $\mathbf{6}$ \\
\hline Cflx & Ccpl & & & & & & \\
\hline \multirow{3}{*}{$\mathbf{1}$} & $\mathbf{1}$ & 2 & 3 & 4 & 5 & 6 & 1 \\
\cline { 2 - 9 } & $\mathbf{0}$ & 1 & 2 & 3 & 4 & 5 & 6 \\
\cline { 2 - 8 } & $\mathbf{- 1}$ & 6 & 1 & 2 & 3 & 4 & 5 \\
\hline \multirow{3}{*}{$\mathbf{0}$} & $\mathbf{1}$ & 3 & 4 & 5 & 6 & 1 & 2 \\
\cline { 2 - 8 } & $\mathbf{0}$ & 4 & 5 & 6 & 1 & 2 & 3 \\
\cline { 2 - 8 } & $\mathbf{- 1}$ & 5 & 6 & 1 & 2 & 3 & 4 \\
\hline
\end{tabular}

The conventional back-emf integration approach of flux estimation can be expressed as $[6,7]$ :

$\overline{\Phi_{S}}=\int_{0}^{t}\left(\overline{V_{S}}-R_{S} \cdot \overline{I_{S}}\right) d t$

During the switching interval, each voltage vector is constant and is then rewritten as in:

$\overline{\Phi_{S}}(k+1) \approx \overline{\Phi_{S}}(k)+\overline{V_{S}} t_{e}$

or

$$
\Delta \overline{\Phi_{S}}(k)=\overline{V_{s}} t_{e}
$$

The electromagnetic torque is proportional to the vectorial product between the stator and rotor flux vector $[8,9]$ :

$$
T e=p \frac{L m}{\sigma_{L_{r} L_{s}}} \Phi_{s} \Phi r \sin \left(\bar{\Phi}_{s} \bar{\oplus}_{r}\right)
$$
by:

The magnitude of stator flux, which can be estimated 
Table 2 Switching table for strategy 1

\begin{tabular}{|c|c|c|c|c|c|c|c|}
\hline \multicolumn{2}{|c|}{ N } & $\mathbf{1}$ & $\mathbf{2}$ & $\mathbf{3}$ & $\mathbf{4}$ & $\mathbf{5}$ & $\mathbf{6}$ \\
\hline Cflx & Ccpl & & & & & & \\
\hline \multirow{3}{*}{$\mathbf{1}$} & $\mathbf{1}$ & 2 & 3 & 4 & 5 & 6 & 1 \\
\cline { 2 - 8 } & $\mathbf{0}$ & 1 & 2 & 3 & 4 & 5 & 6 \\
\cline { 2 - 8 } & $\mathbf{- 1}$ & 1 & 2 & 3 & 4 & 5 & 6 \\
\hline \multirow{3}{*}{0} & $\mathbf{1}$ & 3 & 4 & 5 & 6 & 1 & 2 \\
\cline { 2 - 8 } & $\mathbf{0}$ & 4 & 5 & 6 & 1 & 2 & 3 \\
\cline { 2 - 8 } & $\mathbf{- 1}$ & 4 & 5 & 6 & 1 & 2 & 3 \\
\hline
\end{tabular}

Table 3 Switching table for strategy 2

\begin{tabular}{|c|c|c|c|c|c|c|c|}
\hline \multicolumn{2}{|c|}{ N } & $\mathbf{1}$ & $\mathbf{2}$ & $\mathbf{3}$ & $\mathbf{4}$ & $\mathbf{5}$ & $\mathbf{6}$ \\
\hline \multirow{3}{*}{$\mathbf{C f l x}$} & Ccpl & & & & & & \\
\hline \multirow{3}{*}{$\mathbf{1}$} & $\mathbf{1}$ & 2 & 3 & 4 & 5 & 6 & 1 \\
\cline { 2 - 8 } & $\mathbf{0}$ & 1 & 2 & 3 & 4 & 5 & 6 \\
\cline { 2 - 8 } & $\mathbf{- 1}$ & 6 & 1 & 2 & 3 & 4 & 5 \\
\hline \multirow{3}{*}{$\mathbf{0}$} & $\mathbf{1}$ & 3 & 4 & 5 & 6 & 1 & 2 \\
\cline { 2 - 8 } & $\mathbf{0}$ & 4 & 5 & 6 & 1 & 2 & 3 \\
\cline { 2 - 8 } & $\mathbf{- 1}$ & 4 & 5 & 6 & 1 & 2 & 3 \\
\hline
\end{tabular}

Table 4 Switching table for strategy 3

\begin{tabular}{|c|c|c|c|c|c|c|c|}
\hline \multicolumn{2}{|c|}{ N } & $\mathbf{1}$ & $\mathbf{2}$ & $\mathbf{3}$ & $\mathbf{4}$ & $\mathbf{5}$ & $\mathbf{6}$ \\
\hline Cflx & Ccpl & & & & & & \\
\hline \multirow{3}{*}{$\mathbf{1}$} & $\mathbf{1}$ & 2 & 3 & 4 & 5 & 6 & 1 \\
\cline { 2 - 8 } & $\mathbf{0}$ & 2 & 3 & 4 & 5 & 6 & 1 \\
\cline { 2 - 8 } & $\mathbf{- 1}$ & 6 & 1 & 2 & 3 & 4 & 5 \\
\hline \multirow{3}{*}{$\mathbf{0}$} & $\mathbf{1}$ & 3 & 4 & 5 & 6 & 1 & 2 \\
\cline { 2 - 8 } & $\mathbf{0}$ & 3 & 4 & 5 & 6 & 1 & 2 \\
\cline { 2 - 8 } & $\mathbf{- 1}$ & 3 & 4 & 5 & 6 & 1 & 2 \\
\hline
\end{tabular}

Table 5 Switching table for strategy 4

\begin{tabular}{|c|c|c|c|c|c|c|c|}
\hline \multicolumn{2}{|c|}{ N } & $\mathbf{1}$ & $\mathbf{2}$ & $\mathbf{3}$ & $\mathbf{4}$ & $\mathbf{5}$ & $\mathbf{6}$ \\
\hline Cflx & Ccpl & & & & & & \\
\hline \multirow{3}{*}{1} & $\mathbf{1}$ & 1 & 2 & 3 & 4 & 5 & 6 \\
\cline { 2 - 8 } & $\mathbf{0}$ & 1 & 2 & 3 & 4 & 5 & 6 \\
\cline { 2 - 8 } & $\mathbf{- 1}$ & 6 & 1 & 2 & 3 & 4 & 5 \\
\hline
\end{tabular}

\begin{tabular}{|c|c|c|c|c|c|c|c|}
\hline \multirow{3}{*}{0} & $\mathbf{1}$ & 3 & 4 & 5 & 6 & 1 & 2 \\
\cline { 2 - 8 } & $\mathbf{0}$ & 4 & 5 & 6 & 1 & 2 & 3 \\
\cline { 2 - 8 } & $\mathbf{- 1}$ & 4 & 5 & 6 & 1 & 2 & 3 \\
\hline
\end{tabular}

\section{DIRECT TORQUE CONTROL BASED ON NEURAL NETWORK STRATEGY}

The ANN is trained by a learning algorithm which performs the adaption of weights of the network iteratively until the error between target vector and the output of ANN is less than an error goal the most popular learning algorithm for complex networks the back propagation algorithm and its variants. The latter is implemented by many ANN software packages such as neural network tool box from Matlab. In the case presented in this paper the DTC control strategy has been implemented. ANN has been devised having inputs the torque error, the stator flux error and position of stator flux, and ass out put the voltage space vector to be generated by the inverter. The ANN block then replaces switching table selector block [10]. The general structure of the IM with DTC-ANN using a two-level inverter in each star is represented by Fig. 2 .

The ANN has many models, but the usual model is the multilayer feed forward network using the error back propagation algorithm. Such a neural network contains three layers: input layers, hidden layers and output layers. Each layer is composed of several neurons. The number of the neurons in the input and output layers depends on the number of the selected input and output variables. The number of hidden layers and the number of neurons in each depend on the desired degree of accuracy. In matlab command we generated the simulink block ANN of switching table by "gensim » given this model show Fig. 3.

The structure of the neural network to perform the proposed strategies of DTC applied to IM satisfactorily was a neural network with three linear input nodes, 30 neurones in the hidden layer, and 3 neurons in the output layer, as shown in Fig. 4.

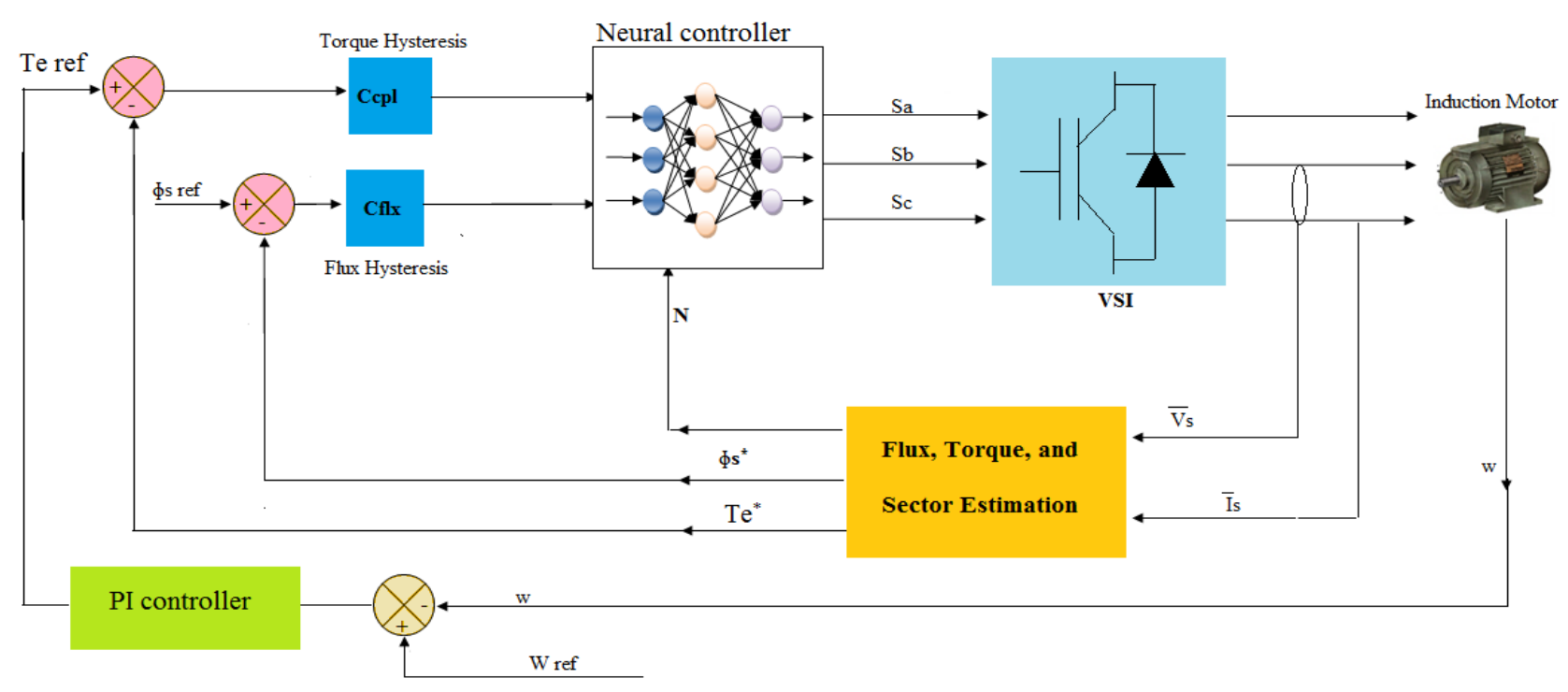

Fig. 2 DTC with ANN 

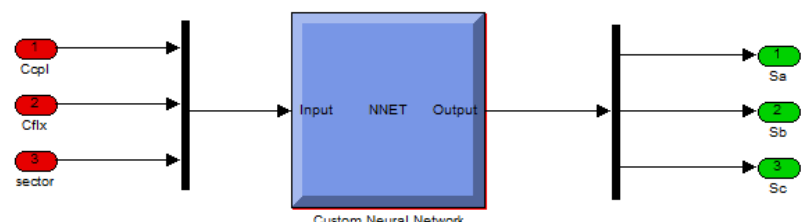

Fig. 3 Simulink block for ANN switching table

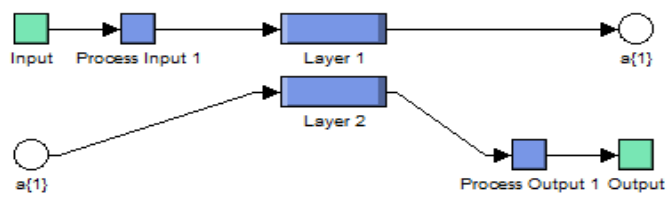

Fig. 4 Neural network structure for proposed strategies

The structure of Layer 1 is shown in Fig. 5.

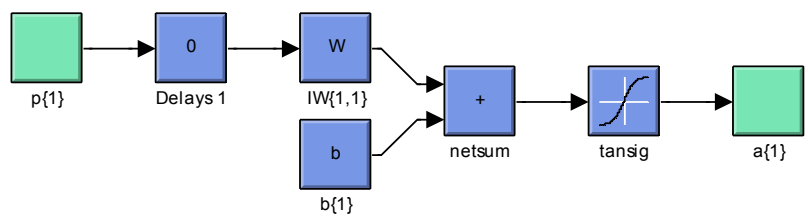

Fig. 5 Architecture of Layer 1

The convergence of the network in summer obtained by using the value of the parameters grouped in the Table 6.

Table 6 Parameters of the LM for proposed strategies

\begin{tabular}{|l|c|}
\hline \multicolumn{1}{|c|}{ Parameters of the LM } & values \\
\hline Number of hidden layer & 30 \\
\hline TrainParam.Lr & 0.002 \\
\hline TrainParam.show & 50 \\
\hline TrainParam.eposh & 5000 \\
\hline $\begin{array}{l}\text { Coeff of acceleration of convergence } \\
(\mathrm{mc})\end{array}$ & 0.9 \\
\hline TrainParam.goal & 0 \\
\hline TrainParam.mu & 0.9 \\
\hline Functions of activation & $\begin{array}{c}\text { Tensing, Purling, } \\
\text { gensim }\end{array}$ \\
\hline
\end{tabular}

\section{SIMULATION RESULTS}

In this paper for case study, $1 \mathrm{MW}, 791 \mathrm{v}, 60 \mathrm{~Hz}$, 3-phase induction motor used for simulating DTC drive. The simulation results are done at rotor speed $1000 \mathrm{rpm}$.

The simulation results of now switching tables of DTC without voltages zeros for induction motor are compared with classical DTC utilizing two-level inverter.

Figs $6,7,8,9$ and 10 show the performance of the induction motor controlled by the proposed strategies of DTC.

Figures 11 to 12 represent the performance of the induction motor commanded by the strategy 1 and strategy 3 with ANN.
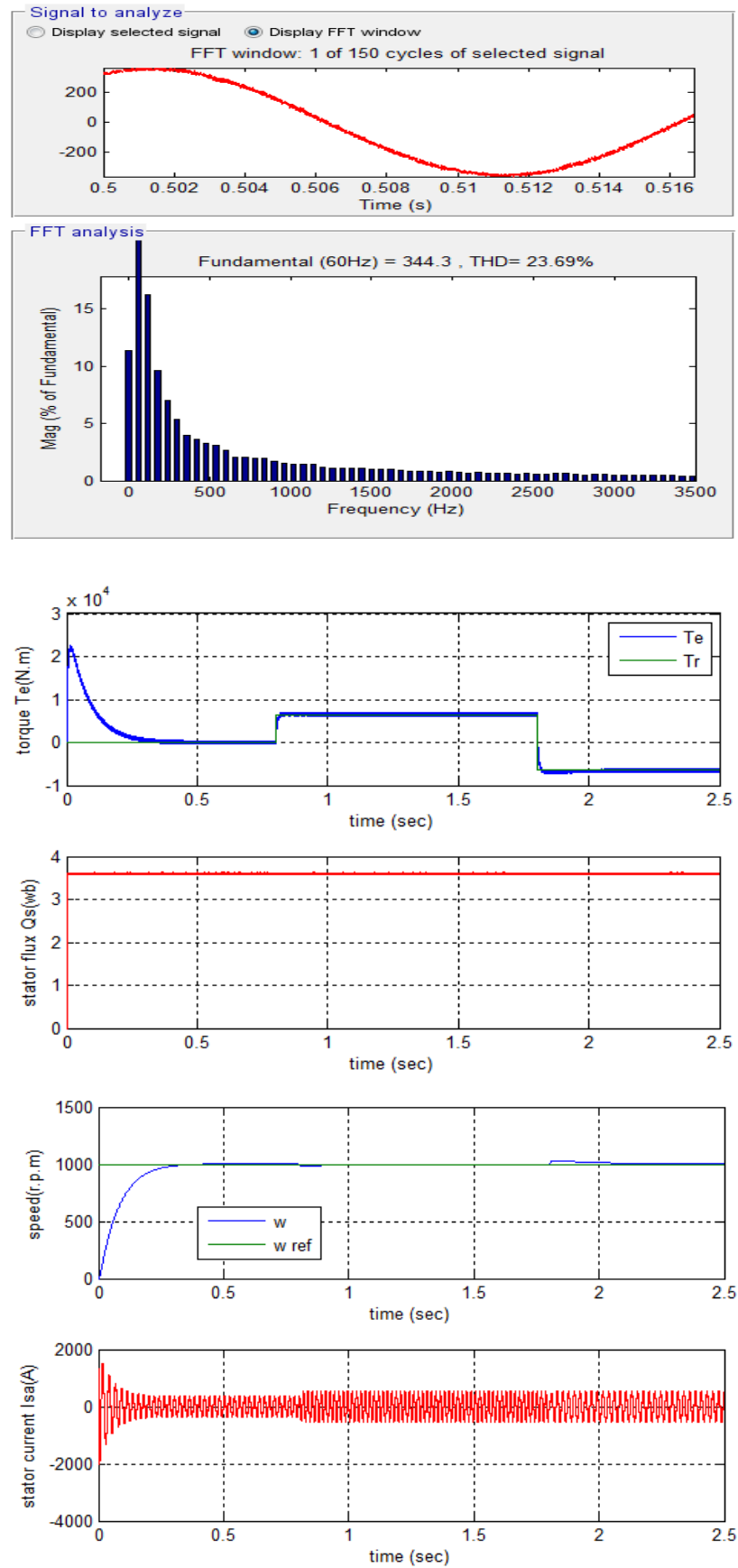

Fig. 6 Dynamic responses of classical DTC for induction motor

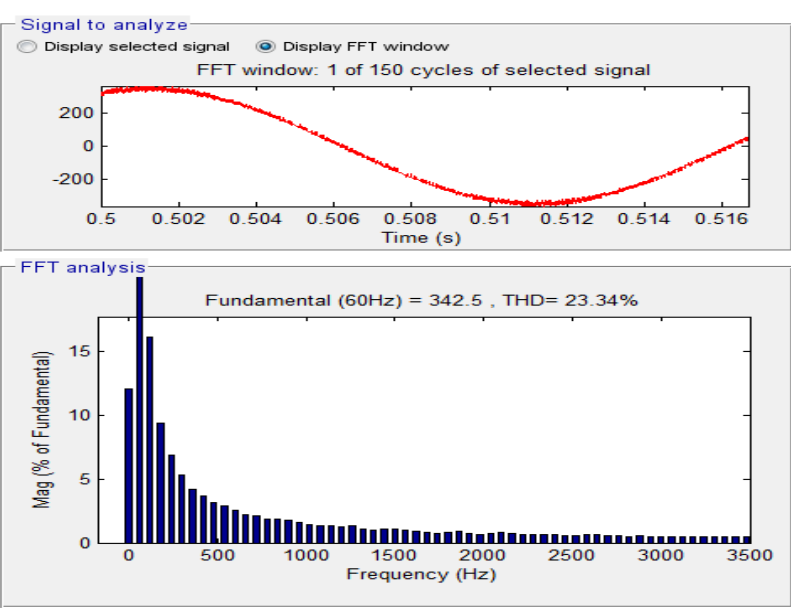



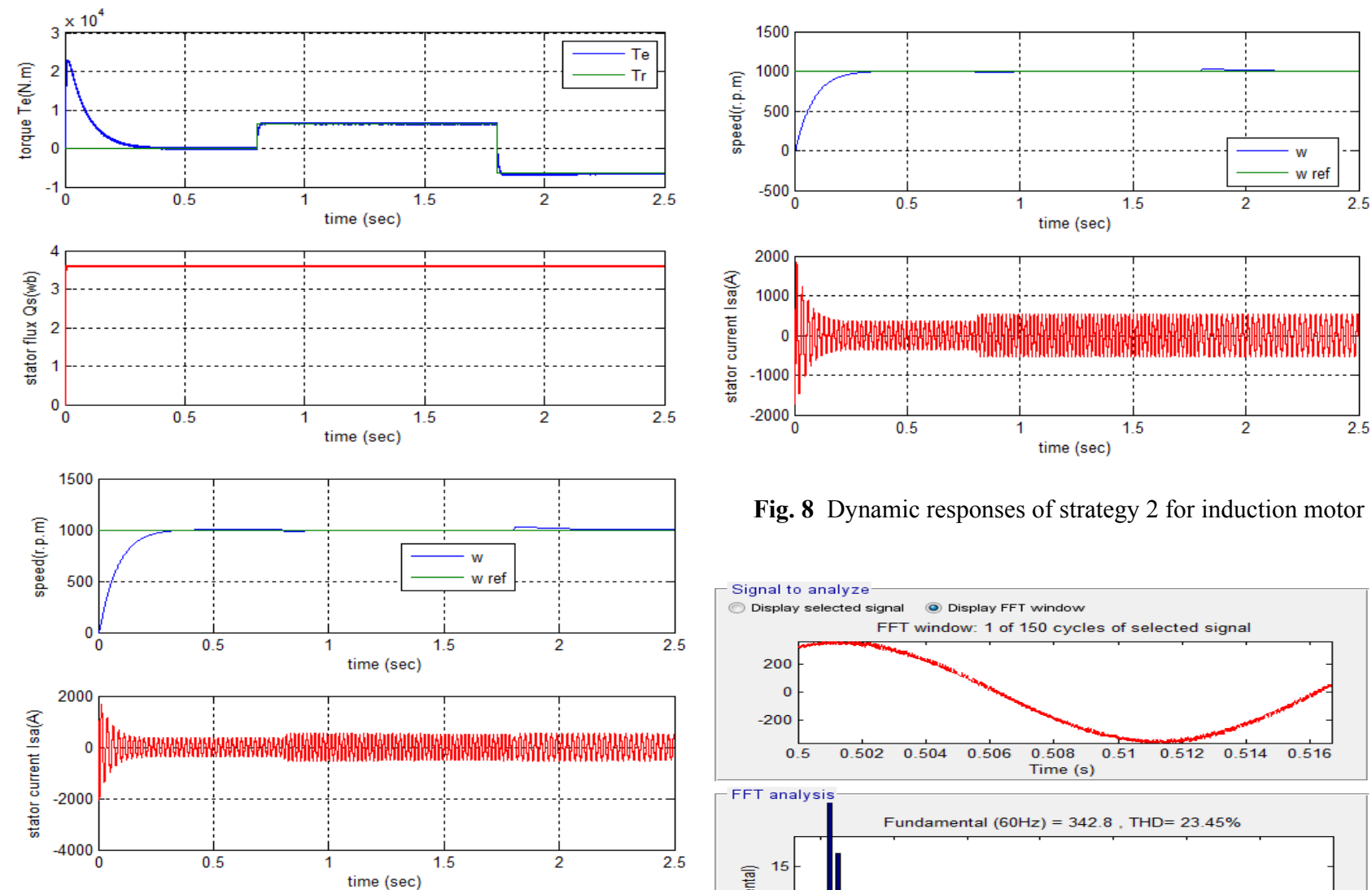

Fig. 8 Dynamic responses of strategy 2 for induction motor

Fig. 7 Dynamic responses of strategy 1 for induction motor.
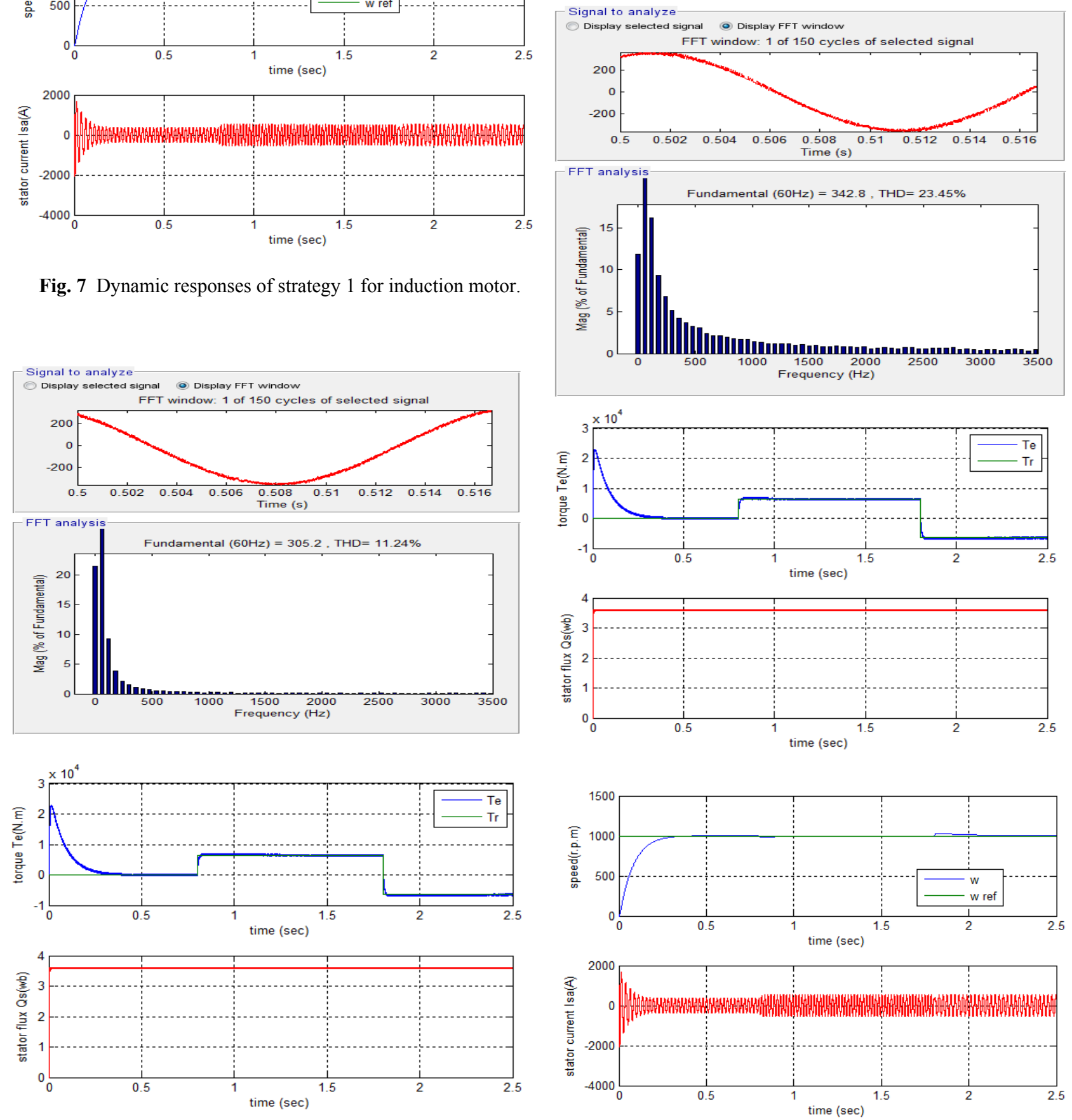

Fig. 9 Dynamic responses of strategy 3 for induction motor 

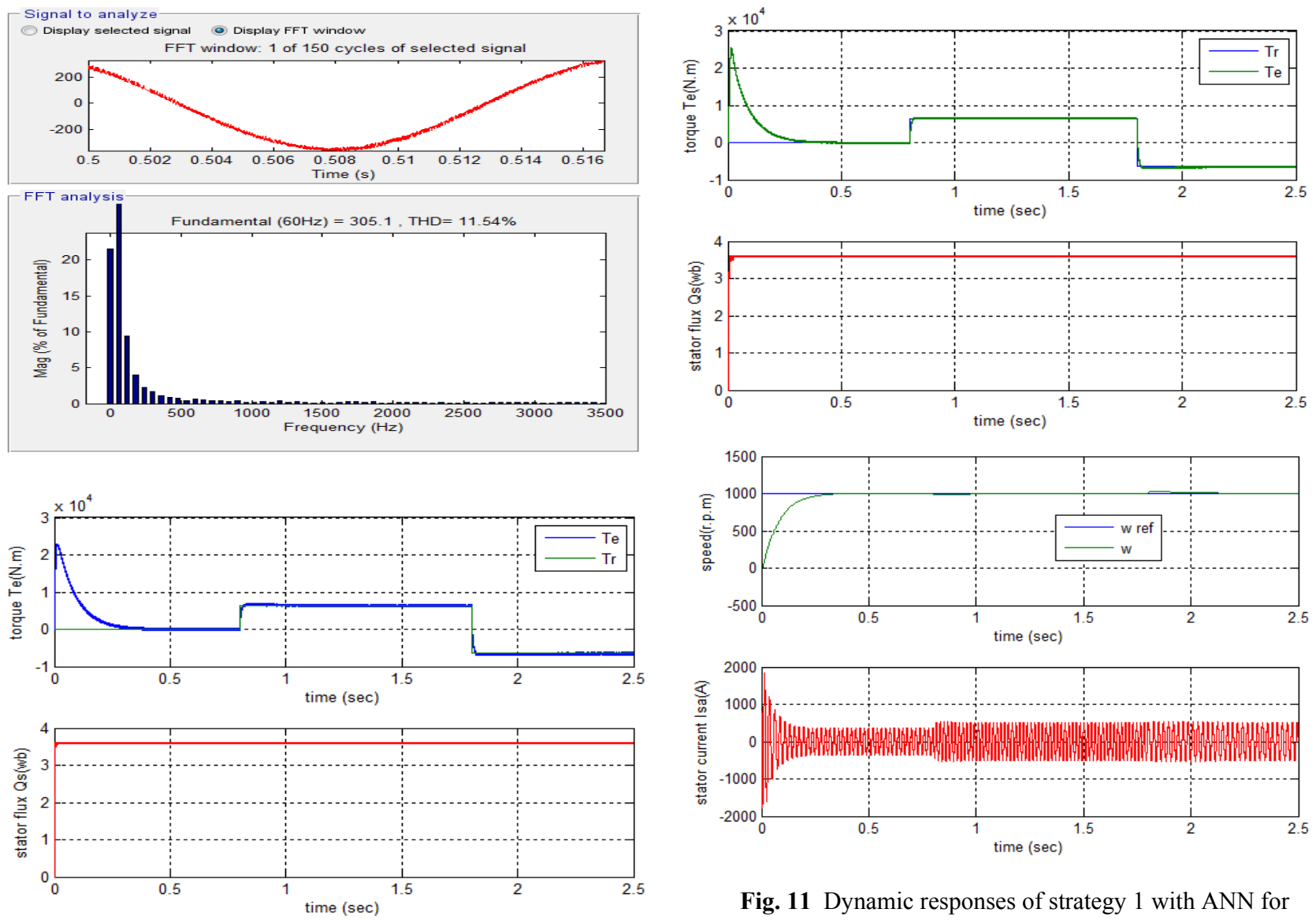

Fig. 11 Dynamic responses of strategy 1 with ANN for
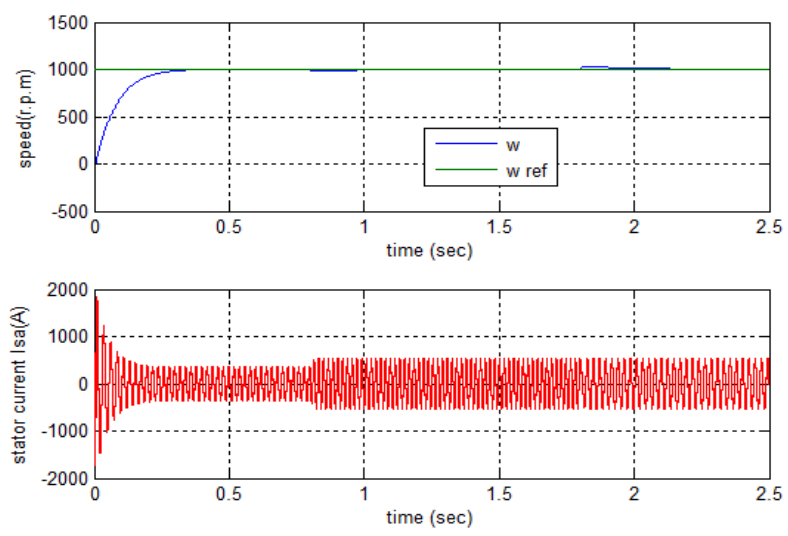

Fig. 10 Dynamic responses of strategy 4 for induction motor
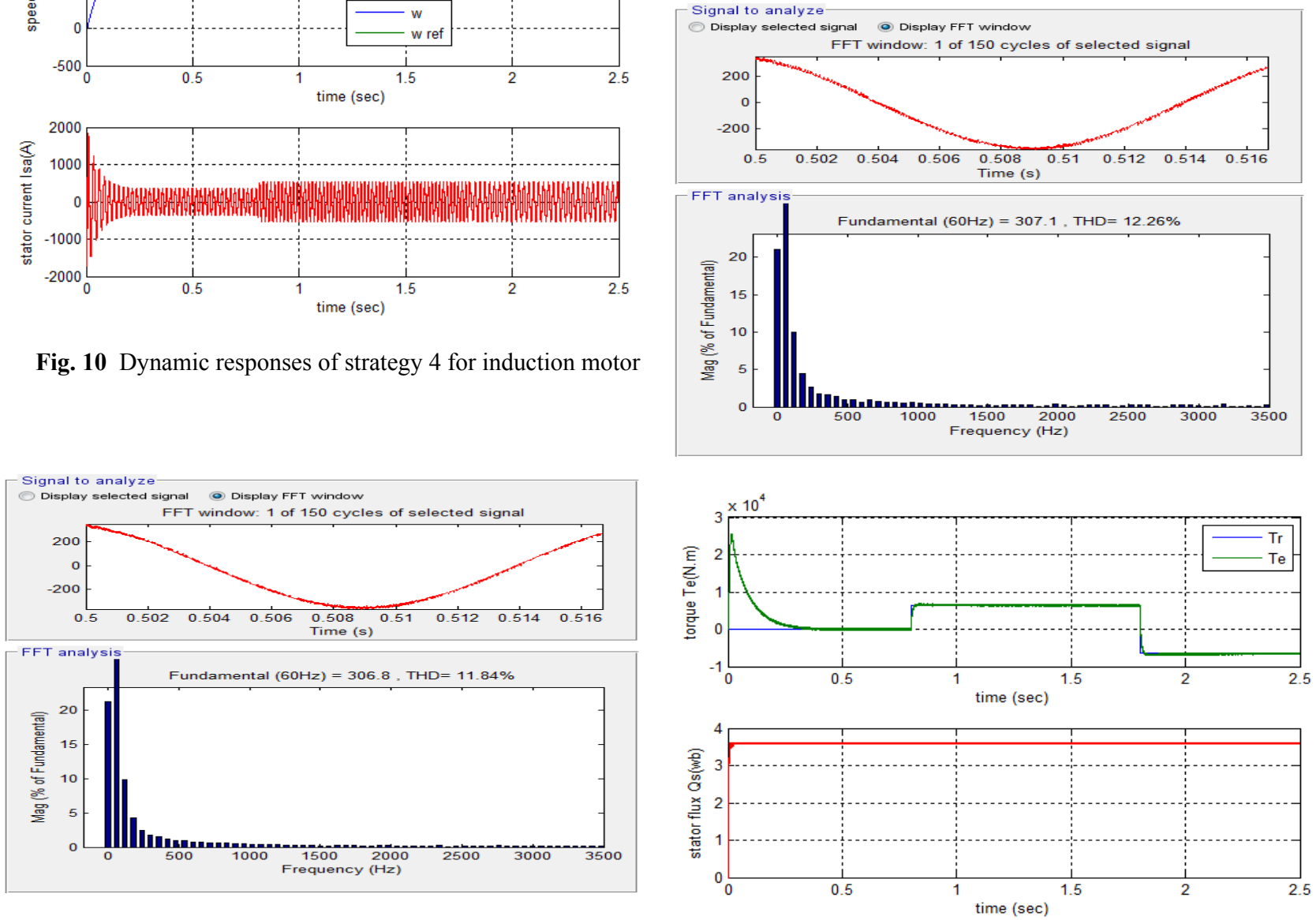

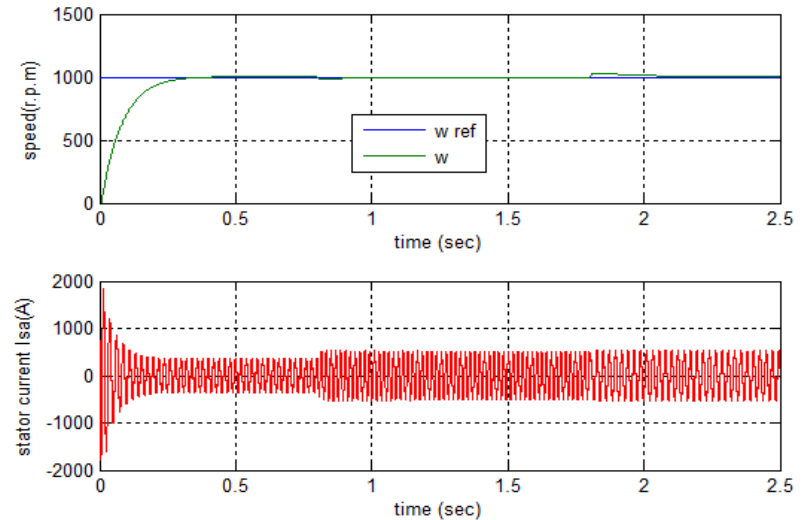

Fig. 12 Dynamic responses of strategy 3 with ANN for induction motor

Table 7 shows the comparative analysis of THD (Total Harmonic Distortion) value of stator current for proposed strategies.

Table 7 Comparative analysis of THD value

\begin{tabular}{|c|c|c|c|c|c|}
\hline & $\begin{array}{c}\text { Classical } \\
\text { DTC }\end{array}$ & $\begin{array}{c}\text { Strategy } \\
1\end{array}$ & $\begin{array}{c}\text { Strategy } \\
2\end{array}$ & $\begin{array}{c}\text { Strategy } \\
3\end{array}$ & $\begin{array}{c}\text { Strategy } \\
4\end{array}$ \\
\hline $\begin{array}{l}\text { Ias } \\
\text { THD } \\
(\%)\end{array}$ & 23.69 & 23.34 & 11.24 & 23.45 & 11.54 \\
\hline
\end{tabular}

From results presented in Table 6 it is apparent that the THD value of stator current for strategy 2 is considerably reduced.

Fig. 13 shows the zooms in the torque of proposed strategies without ANN. Fig. 13 a) shows the torque ripple for classical DTC. Fig. 13 b) shows the torque ripple for strategy 1 . Fig. $13 \mathrm{c}$ ) shows the torque ripple for strategy 2. Fig. 13 d) shows the torque ripple for strategy 3. Fig. 13 e) shows the torque ripple for strategy 4 . This results show that the torque ripple in the strategy 1 has been reduced significantly.

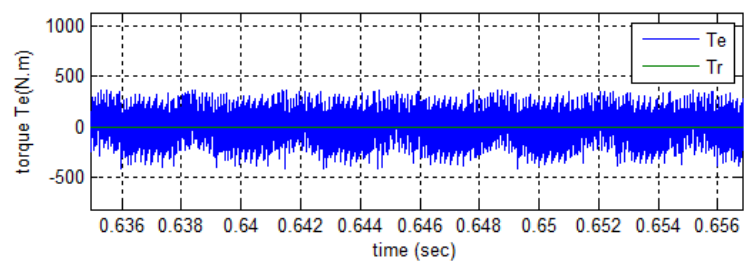

a) Classical DTC

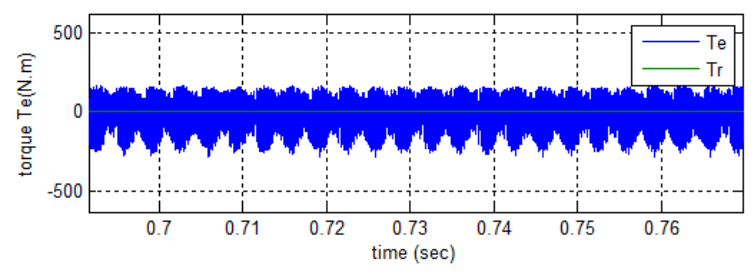

b) Strategy 1

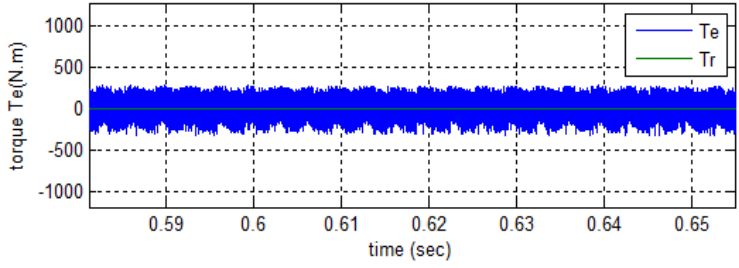

c) Strategy 2

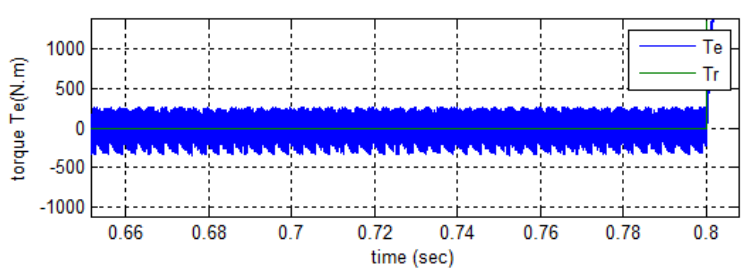

d) Strategy 3

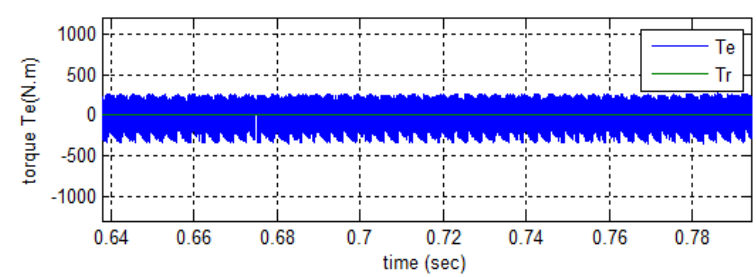

e) Strategy 4

Fig. 13 Zooms in the torque of proposed strategies without ANN

Fig. 14 shows the zooms in the stator flux. This Figure shows that the stator flux ripple in the strategy 2 of DTC scheme has been reduced significantly.

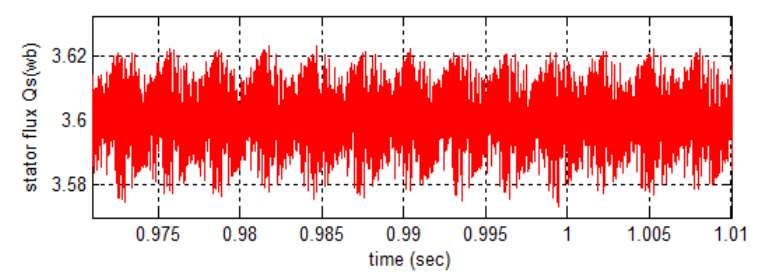

a) Classical DTC

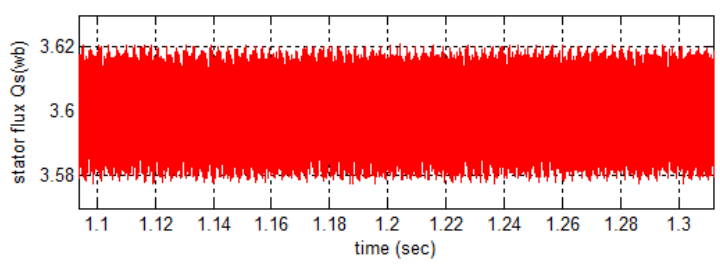

b) Strategy 1

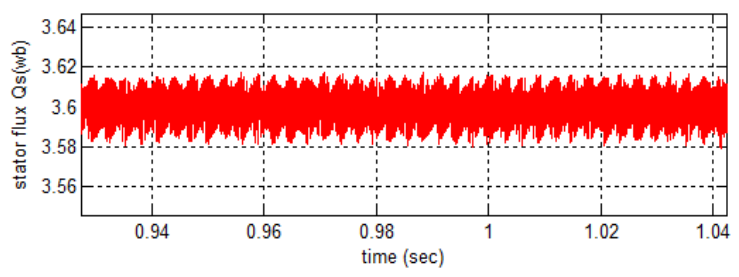

c) Strategy 2 


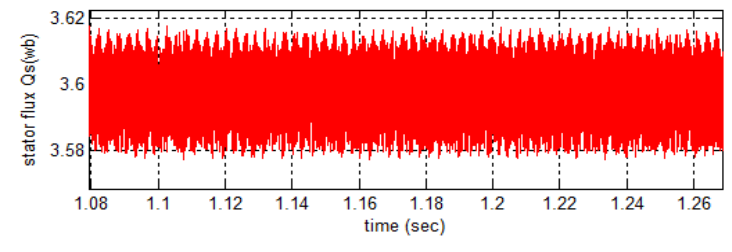

d) Strategy 3

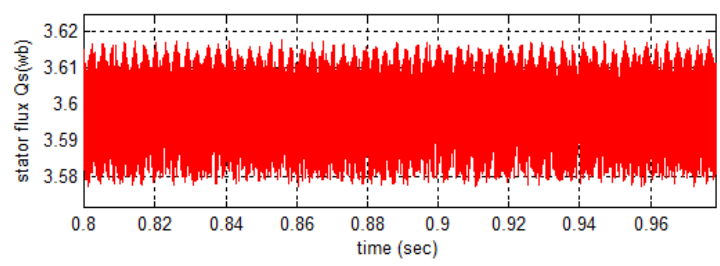

e) Strategy 4

Fig. 14 Zooms in the stator flux of proposed strategies without ANN

Table 8 shows the comparative analysis of THD (Total Harmonic Distortion) value of stator current for proposed strategies (strategy 1 and strategy 3) with ANN. The use of ANN has improved the THD value of stator current.

Table 8 Comparative analysis of THD value

\begin{tabular}{|c|c|c|c|c|}
\cline { 2 - 5 } \multicolumn{1}{c|}{} & $\begin{array}{c}\text { Strategy } \\
1\end{array}$ & $\begin{array}{c}\text { Strategy } \\
3\end{array}$ & $\begin{array}{c}\text { Strategy 1 } \\
\text { with ANN }\end{array}$ & $\begin{array}{c}\text { Strategy 3 } \\
\text { with ANN }\end{array}$ \\
\hline $\begin{array}{c}\text { Ias } \\
\text { THD } \\
(\%)\end{array}$ & 23.34 & 23.45 & $\mathbf{1 1 . 8 4}$ & $\mathbf{1 2 . 2 6}$ \\
\hline
\end{tabular}

The Fig. 15 shows the good compensation of the stator flux ripple by using the Artificial Neural Network (ANN). This flux was restored correctly with its reference.

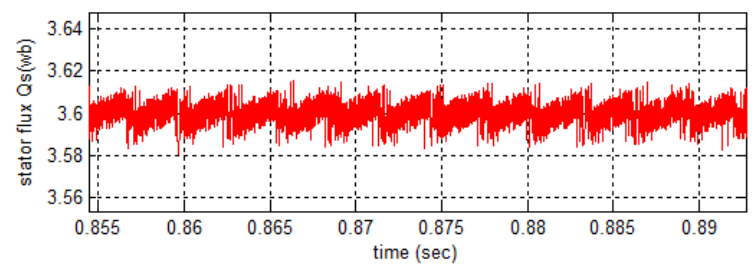

a) Strategy 1 with ANN

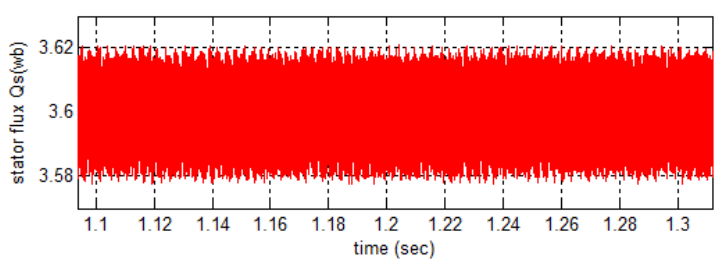

b) Strategy 1

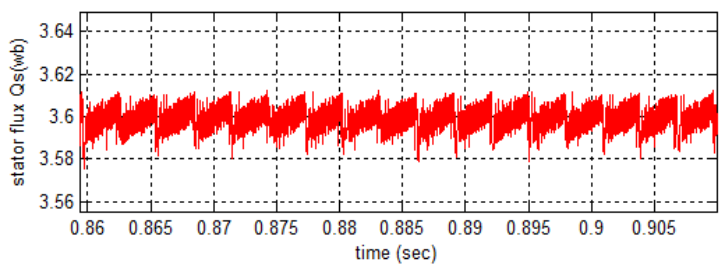

c) Strategy 3 with ANN

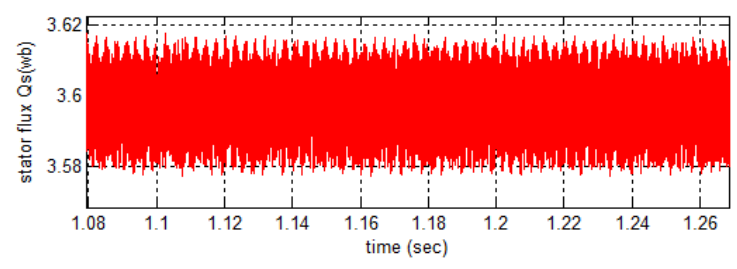

d) Strategy 3

Fig. 15 Comparative analysis of stator flux ripples

The use of ANN has improved the band electromagnetic torques are shown in Fig. 16.

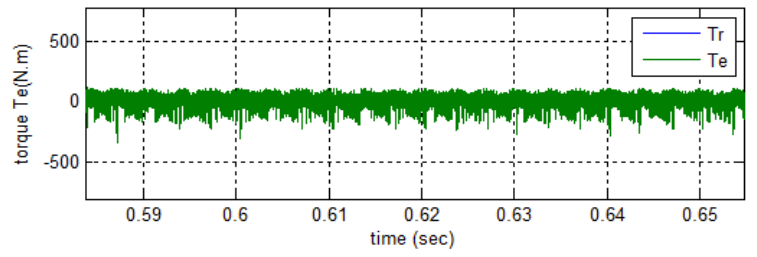

a) Strategy 1 with ANN

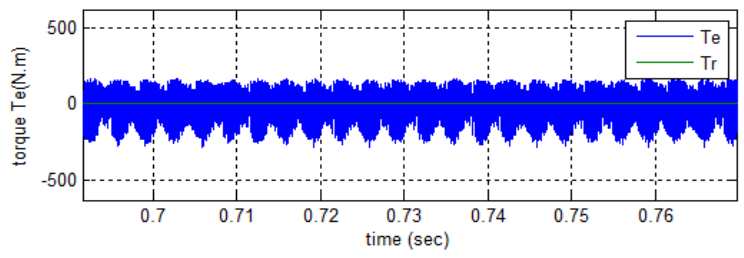

b) Strategy 1 without ANN

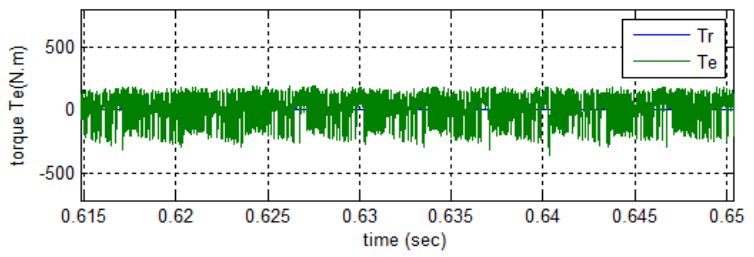

c) Strategy 3 with ANN

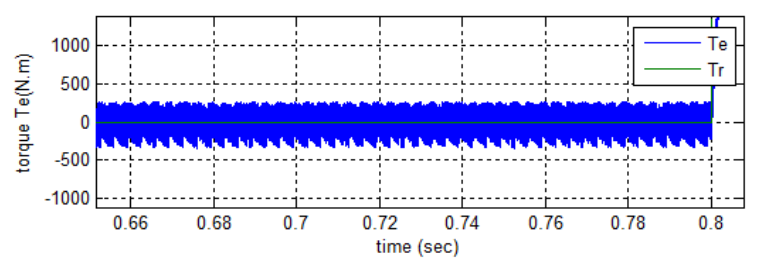

d) Strategy 3 without ANN

Fig. 16 Comparative analysis of torque ripples

\section{CONCLUSIONS}

The paper presents simulation of a new switching tables (proposed strategies) of DTC scheme for induction motor drives (1MW) using artificial neural network. The comparaisons through simulations between classical DTC control and proposed strategies for IM drive have been done. This simulation based on Matlab has represented the behaviour of DTC for IM drive clearly and correctly. The simulation result has shown that the reduction of flux ripple, torque ripple and THD value of stator current can be achieved through the strategy 2 . On other hand, using ANN reduces the torque ripple, stator flux ripple and THD 
value of stator current of IM performance compared to obtain with a conventional strategies.

The simulation results obtained were satisfactory, and system stability has been insured.

\section{APPENDIX}

Table 9 Induction motor parameters

\begin{tabular}{|c|l|c|}
\hline Symbole & \multicolumn{1}{|c|}{ Quantity } & Numerical value \\
\hline $\mathrm{P}$ & Power & $1 \mathrm{MW}$ \\
\hline $\mathrm{f}$ & Supply frequency & $60 \mathrm{~Hz}$ \\
\hline $\mathrm{V}$ & Supply voltage & $791 \mathrm{v}$ \\
\hline $\mathrm{Rs}$ & Stator resistance & $0.228 \Omega$ \\
\hline $\mathrm{Rr}$ & Rotor resistance & $0.332 \Omega$ \\
\hline $\mathrm{Ls}$ & Stator inductance & $0.0084 \mathrm{H}$ \\
\hline $\mathrm{Lr}$ & Rotor inductance & $0.0082 \mathrm{H}$ \\
\hline $\mathrm{M}$ & Mutual inductance & $0.0078 \mathrm{H}$ \\
\hline $\mathrm{J}$ & Inertia coefficient & $20 \mathrm{~kg} . \mathrm{m} 2$ \\
\hline $\mathrm{Fr}$ & Friction coefficient & $0.008 \mathrm{SI}$ \\
\hline $\mathrm{Tr}$ & Load torque & $6500 \mathrm{~N} . \mathrm{m}$ \\
\hline
\end{tabular}

\section{REFERENCES}

[1] LALL, K. P. - SABAH, V. S. - BABY, T. C. CHITRA, A.: Comparative analysis of VSI \& 7 level MLI fed induction motor drive with IFOC scheme and pump load, Journal of Engineering Research and Applications, Vol. 4, Issue 7, pp. 100-107, Jul. 2014.

[2] MANUEL, A. - FRANCIS, J.: Simulation of direct torque controlled induction motor drive by using space vector pulse width modulation for torque ripple reduction, International Journal of Advanced Research in Electrical, Electronics and Instrumentation Engineering, Vol. 2, Issue 9, Sep. 2013.

[3] ACHARI, K. N. -GURURAJ, B. - ASHOK KUMAR, D. V. - KUMAR, M. V.: A novel Matlab/Simulink model of PMSM drive using direct torque control with SVM, International Conference on Emerging Technology Trends on Advanced Engineering Research (ICETT'12) Proceedings Published by International Journal of Computer Applications (IJCA), 2012.

[4] BENYOUSSEF, E. - MEROUFEL, A. - BARKAT, S.: Three-level DTC based on fuzzy logic and neural network of sensorless DSSM using extende kalman filter, International Journal of Power Electronics and Drive System (IJPEDS), Vol. 5, No. 4, pp. 453463, Apr. 2015.

[5] AMMAR, A. - BOUREK, A. - BENAKCHA, A.: Implementation of sensorless direct torque control of induction motor using sliding mode observer, International Conference on Automatic Control, Telecommunications and Signals (ICATS15), University Badji Mokhtar - Annaba, Algeria, Nov. 16-18, 2015.

[6] DOUIRI, MY. R. - NASSER, T. - ESSADKI, A. CHERKAOUI, M.: Direct torque controle of induction motor based on artificial neural networks with estimate regulation speed using the MRAS and neural PI controller, Journal of Theoretical and Applied Information Technology (JATIT), 2010.

[7] TOUFOUTI, R. - MEZIANE, S. - BENALLA, H.: Direct torque control for induction motor using intelligent techniques, Journal of Theoretical and Applied Information Technology (JATIT), 2007.

[8] MESSAOUDI, B.: Utilisation du contrôle directe du flux statorique et du filtre de kalman en vue du contrôle directe du couple d'un moteur asynchrone, Mémoire de Magister, université Mohamed Khider de Biskra, 2007.

[9] RIAD, T.: Contribution à la commande directe de couple d'une machine asynchrone triphasée, Thèse de Doctorat, université Mentouri Constantine, 2008.

[10] YOUSEF, D.: Commande directe du couple et des puissances d'une MADA associée à un système éolien par les techniques de l'intelligence artificielle, Thèse de Doctorat en Science, université Djillali Liabes de Sidi Belabbes, 2015.

Received October 3, 2017, accepted February 2, 2018

\section{BIOGRAPHY}

Habib Benbouhenni was born in Chlef, Algeria. He is a $\mathrm{PhD}$ student in the Departement of Electrical Engineering at the ENPO-MA, Oran, Algeria. He received a M.S. degree in automatic and informatics industrial in 2017. His research activities include the application of robust command in the wind turbine power systems. 